\title{
Satellite Data for Structural Monitoring of Historical Building: The Temple of Minerva Medica in Rome
}

\author{
MARIA FRANCESCA SABBÀ, MICHELA LERNA, MARIELLA DIAFERIO, DORA FOTI \\ Dept. of Civil Engineering and Architecture and Dept. of Civil, Environmental, Land, Construction \\ and Chemistry \\ Polytechnic University of Bari \\ Via Orabona n. 4 \\ ITALY
}

\begin{abstract}
The Differential Synthetic Aperture Radar Interferometry is a remote sensing technique to acquire deformation velocity and displacement time-series of large territorial areas. The aim of this work is to develop operational methodologies that allow to assess the structures conservation state by integrating information from traditional monitoring systems with the remote sensing application, in order to monitor permanently structures and infrastructure with a historical relevance and developing specific maintenance programs. It is verified that this processing technique is an adequate tool, even in real-time, to monitor any damage or potential critical issues in the case of exceptional events such as earthquakes or landslides. The case study is the Temple of Minerva Medica in Rome, a masonry building characterized by an important historical-artistic value. The dataanalysis shows as the use of satellite monitoring can be a valid tool for the structural safety, allowing to identify a vulnerability map of archaeological sites and historical buildings. The data interferometric processing was carried out using a Graphic Information System (GIS) software.
\end{abstract}

Key-Words: - Aperture Radar Interferometry (DInSAR), Structural Monitoring, Historical Building.

Received: June 15, 2021. Revised: November 17, 2021. Accepted: December 10, 2021. Published: December 31, 2021.

\section{Introduction}

Archaeological monuments are frequently subjected to environmental phenomena with direct and indirect impacts, often worsening. These problems can be of particular concern above all for the management of those sites characterized by a high density of heritage, so it becomes difficult, as well as expensive, an ordinary maintenance effective to prevent structural instability events.

In this regard, it becomes necessary to define sustainable asset management strategies by the use of technologies capable of detecting conservational criticisms, on extended survey areas and providing highly detailed information. It is possible by the availability of huge spatial radar data archives, including those acquired in the last two decades from the synthetic opening radar sensors (SAR) through European Space Agency (ESA)'s ERS-1/2 and ENVISAT missions [1].

Among the remote sensing techniques, the synthetic opening radar interferometry based on the processing of images acquired by spatial radar sensors has the potential to become a routine method for the preventive diagnosis of archaeological heritage, at various scales of analysis, from the whole site to the single monument. The processing approaches (Persistent Scatterer Interferometry (PSI)) allow reconstructing superficial deformations that affect the land and artificial structures in temporal and spatial evolution [2-3]. The processed satellite images allow generating persistent Measuring Points (MP) for the whole monitoring period obtaining a deformation time series.

In particular, the Differential Synthetic Aperture Radar Interferometry (DInSAR) has demonstrated to be an effective tool for non-invasive deformation analysis on vast areas producing spatially dense deformation maps with a highly precision level. Furthermore, using long data sequences acquired from different sensors, the Advanced DInSAR technique called Small Baseline Subset (SBAS) approach allows to provide long-term deformation time series to ensure the monitoring of the movement of the urban area [4-8].

In recent years the city of Rome with its vast archaeological heritage, has been chosen to test the effectiveness of interferometric techniques for the preventive diagnosis of deformation that threatens the structural stability of archaeological sites, through the study of satellite data collected with different satellite interferometry techniques. 
Traditional SAR interferometry can estimate movements with an accuracy of the centimeter order; it is important to emphasize that generally does not allow to carry out punctual estimates, but only together analysis to identify macroscopic phenomena in place (extension> $0.2 \mathrm{~km} 2$ ). To contain these phenomena, in the '90s the advanced interferometric techniques (Advanced DInSAR ADInSAR) have been developed that use a series of radar images related to the same area on which different radar targets are identified, used to measure displacements. This technique provides the complete description of the temporal evolution of the deformations by avoiding the sampling of the phenomenon through the study of two different acquisitions (master and slave). Thus, the multiinterferogram technique is based on the definition of permanent reflectors (Persistent Scatters-PS) onsite, capable of not altering their electromagnetic properties for any geometric and climatic conditions, thus preserving the phase information over time [3].

This research aims to develop techniques and operational protocols for the integration of the information acquired through satellite data with those acquired by traditional on-site non-destructive monitoring technologies [9-11], in order to allow monitoring permanently of the health-state of structures and infrastructure, as well as cultural relevance goods, programs extraordinary maintenance and evaluate, even real-time, any damage or potential criticalities in the case of exceptional events.

\section{DInSAR - SBAS Technic}

The DInSAR - SBAS approach, applied to data collected by ES-1 and ERS-2 radar systems, allows the study of soil deformation on two distinct spatial scales, to extend the temporal coverage of monitored phenomena. The acquisitions are carried out on:

- Low-resolution regional scale, which exploits medium interferograms (multilook) and generates average deformation speed maps and the corresponding time series related to very large areas (about $\mathrm{km}$ $100 \times 100$ ), with a ground resolution typically about $\mathrm{m} 100 \times 100$ [8].

- Local scale, with full resolution, which exploits interferograms (single-look) generated with full spatial resolution (5-10 $\mathrm{m})$, to detect and analyze local deformation on individual buildings and artificial structures [8].
The key steps to recover movement time series are:

1. Choice of pairs of data used for generating interferograms in order to mitigate the phenomena of operation. In this phase, constraints are introduced on the spatial and temporal baseline between the orbits for the acquisition of images will be, in order to maximize the number of pixels coherent in multi-look interferograms;

2. Recovery phase, named "phase unlock" of the original phase. This operation allows us to process the data available on a grid, useful in order to improve the performance of the algorithm in areas with relatively low coherence values;

3. Combination of interferograms with the Singular Value Decomposition (SVD) method which allows to regularize the problem and generate the minimum standard solution that guarantees a valid solution;

4. Space-temporal filtration able to estimate and remove artifacts due to atmospheric inhomogeneities between acquisition pairs. This operation is based on the observation that the phase component of the atmospheric signal is highly related in space but scarcely over time and allows correcting these errors without the need to obtain additional information from the ground [7].

\section{Case of Study}

The monumental building of study case is commonly known as "Temple of Minerva Medica" and is located in Rome at altitude 50.7 m S.L.M., near Termini station and a urban trams passage. The archaeologists believe that it was an ancient nymphaeum of the 4th century D.C, connected to the water supply network. It is a masonry building with a decagonal plant of the diameter of $25 \mathrm{~m}$, covered by a dome with a maximum height of $32 \mathrm{~m}$ (Fig. 1(a)). On each side, except the entrance on the north-west side, semi-circular niches of variable depth of $4.28 \mathrm{~m}$ to $4.65 \mathrm{~m}$ are positioned. Above these, there are arched windows (Fig. 1(b)). Ten pillars support the dome, which, starting from a polygonal shape gradually assumes a hemispherical appearance. There are ten main ribs and secondary winds that give it the "umbrella" appearance.

The ribs are made up of five parallel brick layers that become three at the top of the dome, where the concrete is replaced by pumice and mortar to lighten the weight. The ribs were elevated simultaneously with the concrete flow casting and arranged in 
horizontal layers and were used to create the frame for the concrete casting (Fig. 1(c)).

Outside the dome consists of five large angular steps that rest on the decagonal drum with the high of $1.53 \mathrm{~m}$. In the 1828 , the structure suffered a slow and constant degradation with the collapse of the dome took place then submitted to a restoration intervention in the 1940s. Since then, only partial interventions were carried out, mostly of maintenance of a buffer of localized structural problems.
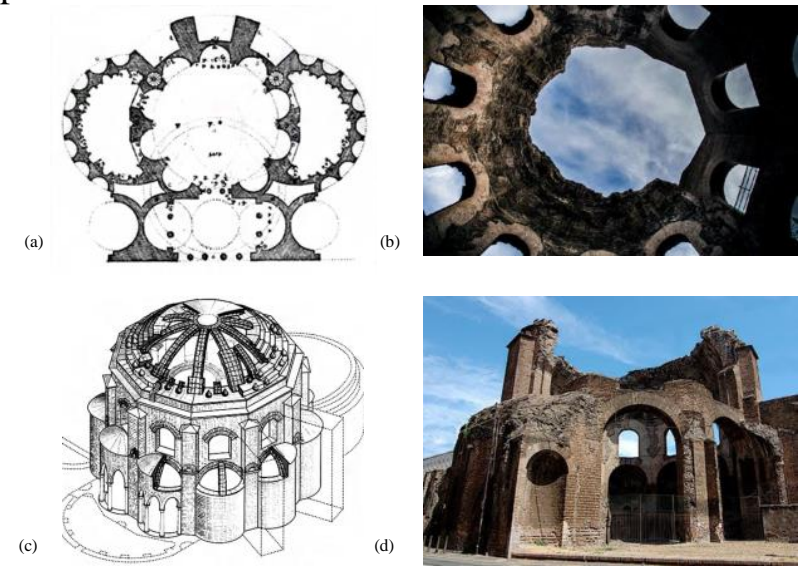

Fig. 1: Minerva Temple: (a) Plan, (b) dome; (c) 3D reconstruction,

(d)

Side

view

[https://www.romanoimpero.com/2015/02/ tempiodi-minerva-medica.html].

Crack patterns are present in the pillars foundation structures, due to the modest stiffness levels of soil, the high levels of stress transmitted on the pillars, the presence of older structures. As regards the classification of the seismic danger of the site, the Italian Technical Code Standard [12] suggests identifying the reference period" VR expressed as the product of $\mathrm{V}_{\mathrm{n}}$ the structural nominal life and $\mathrm{C}_{\mathrm{U}}$ the coefficient of use. Given the extraordinary opening of the Temple for guided tours organized by the Special Superintendency Authority of Rome, a coefficient of use equal to 0.7 corresponding to Class I was chosen.

The Temple is characterized by a seismic acceleration on the ground equal to $0.10-15 \mathrm{~g}$, referred a $10 \%$ probability of overcoming in 50 years. To define the seismic design action, the effect of the local seismic response can be assessed by a simplified approach that is based on the classification of the subsoil according to the values of the propagation speed of the $\mathrm{V}_{\mathrm{S}}$ shear waves, obtained by specific tests. Furthermore, the site is located at a topographic average quote of $50.7 \mathrm{~m}$ S.L.M. and has morphology of type T1 category [12].

\subsection{Analysis of Satellite Monitoring Data}

The results obtained from the processing of data collected by ASI for the municipality of Rome provided by the Italian National Research Council (CNR), are archived in a database which reports, for each identified PS, a series of information relating to the time interval considered. The identified points are returned on a grid of $\mathrm{m} 0.87 \times 1.1$ and refer to a resolution cell of about $\mathrm{m} 2.7 \times 2.8$ with a sampling done on a grid of $\mathrm{m} 2.2 \times 2.2$ (Fig. 2). The dataset covers the period between 2011 and 2019 with a time shift of 4 months.

Within the database provided by CNR and acquired by ASI, the ASCII files containing the satellite data acquired from the ascending and the descending orbit, relating to the Temple of Minerva Medica, have been selected. The open-source geographic information system QGis 3.10 A Coruña has been adopted for the analysis. Among the monitored parameters, the mean annual deformation speed expressed in $\mathrm{cm} /$ year was considered. It was possible to organize, study and process the points by editing the symbols of the individual points and classify them according to the range of values significant for the analysis of both the ascending and descending satellite orbit. Fig.s 3-4 show the distributions of the values of the annual velocities ( $\mathrm{cm} /$ year) relative to the two satellite orbits.



Fig. 2: Representation of the geodified grid (black) and sampling grid (orange).

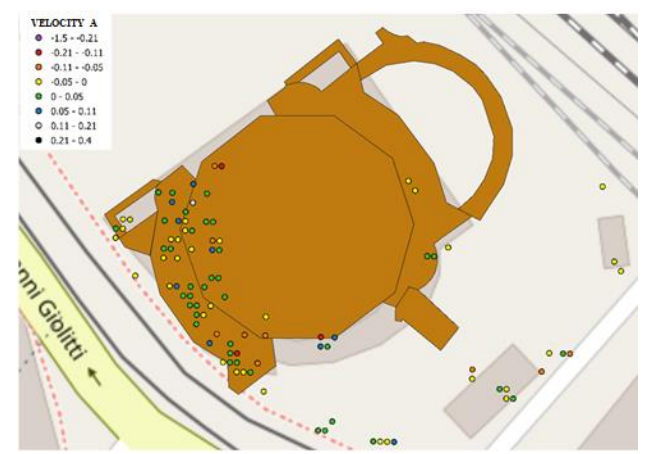

Fig. 3: Spatial distribution of annual velocity values (cm/year) relating to the ascending orbit [QGis3.10 A Coruña] 


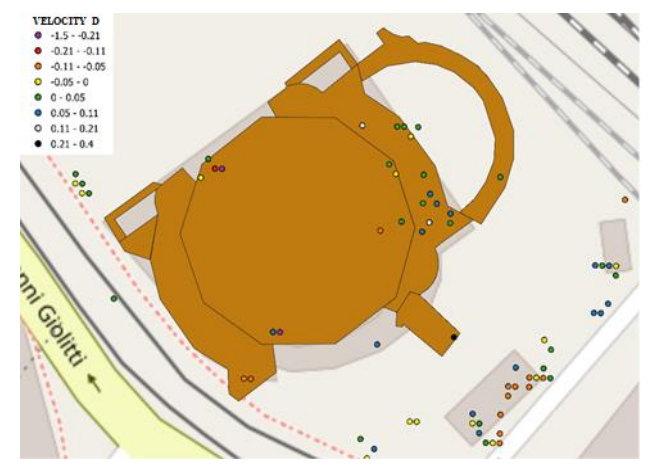

Fig. 4: Spatial distribution of annual velocity values (cm/year) relating to the descending orbit [QGis3.10 A Coruña]

A subsequent processing of the satellite measurements relating to annual velocity values (vel) is aimed at evaluating the actual distribution of the points measured within the identified intervals (see the results in Tables 1-2).

Points 108 and 87 were monitored, respectively, for the ascending and descending orbit. In the first case, $35 \%$ of the points detected with annual velocity values in a range of $0-0.14 \mathrm{~cm} /$ year ( 20 points out of 57 total) exceed the average value of $\sim 0.03$ $\mathrm{cm} /$ year, while $61 \%$ of the points with velocity values between -0.19 and $0 \mathrm{~cm} /$ year (31 points out of 51 total) exceed the average value equal to $0.035 \mathrm{~cm} /$ year.

In the second case, $44 \%$ of the points detected with annual velocity values between 0 and $0.27 \mathrm{~cm} /$ year ( 23 points out of 52 total) exceed the average value of $\sim 0.05 \mathrm{~cm} /$ year, while $63 \%$ of the points with velocity values in the range of $-0.34-0 \mathrm{~cm} /$ year $(22$ compared to the total 35) exceed the average value of $\sim-0.07 \mathrm{~cm} /$ year.

Table 1 . Velocity distribution relative to the ascending orbit

\begin{tabular}{|ll|c|}
\hline Velocity Range & Number of points \\
\hline $\mathrm{cm} /$ yaer & \\
$-1.50<$ vel $<-0.21$ & (violet) & 0 \\
$-1.21<$ vel $<-0.11$ & (red) & 10 \\
$-1.11<$ vel $<-0.05$ & (orange) & 38 \\
$-0.50<$ vel $<0.00$ & (yellow) & 46 \\
$0.00<$ vel $<0.05$ & (green) & 10 \\
$0.05<$ vel $<0.11$ & (blue) & 1 \\
$0.11<$ vel $<0.21$ & (grey) & 0 \\
$0.21<$ vel $<0.40$ & (black) & 0 \\
\hline
\end{tabular}

Table 2. Velocity distribution relative to the descending orbit

\begin{tabular}{|c|c|}
\hline Velocity Range & Number of points \\
\hline $\mathrm{cm} /$ yaer & \\
\hline$-1.50<$ vel $<-0.21 \quad$ (violet $)$ & 3 \\
\hline$-1.21<$ vel $<-0.11 \quad(\mathrm{red})$ & 2 \\
\hline$-1.11<$ vel $<-0.05 \quad$ (orange) & 14 \\
\hline
\end{tabular}

\begin{tabular}{|c|c|c|}
\hline$-0.50<\mathrm{vel}<0.00$ & (yellow) & 17 \\
\hline $0.00<\mathrm{vel}<0.05$ & (green) & 27 \\
\hline $0.05<$ vel $<0.11$ & (blue) & 20 \\
\hline $0.11<$ vel $<0.21$ & (grey) & 3 \\
\hline $0.21<\operatorname{vel}<0.40$ & (black) & 1 \\
\hline
\end{tabular}

The second monitored parameter is the Consistency (con); it is an indicator relating to the reliability of the satellite measurement. The distribution of the points observed at the consistency value changes is shown in Fig.s 5-6 and in Tables 3-4.



Fig. 5: Distribution of monitored points as the consistency variation relating to the ascending orbit [QGis3.10 A Coruña]

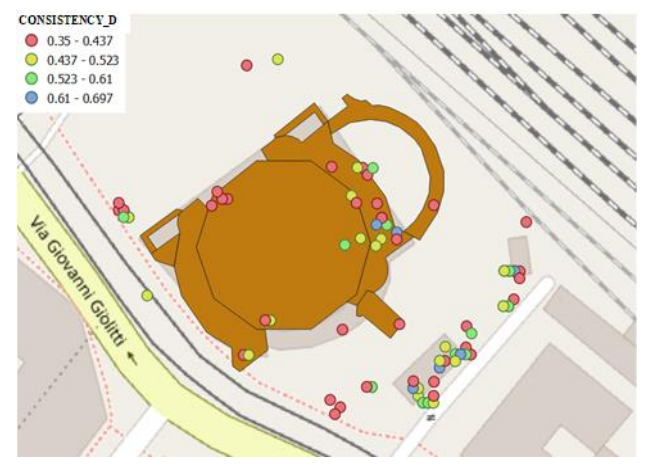

Fig. 6: Distribution of monitored points as the consistency variation relating to the descending orbit [QGis3.10 A Coruña]

Table 3. Distribution of points based on the value of consistency - ascending orbit

\begin{tabular}{|l|c|}
\hline Consistency Range & Number of points \\
\hline $0.351<$ con $<0.395$ & (red) \\
$0.395<$ con $<0.460$ & (yellow) \\
$0.460<$ con $<0.533$ (green) & 26 \\
$0.533<$ con $<0.798$ (blue) & 23 \\
\hline
\end{tabular}

Table 4. Distribution of points based on the value of consistency - descending orbit

\begin{tabular}{|c|c|}
\hline Consistency Range & Number of points \\
\hline $0.350<$ con $<0.437$ (red) & 40 \\
\hline $0.437<$ con $<0.523$ (yellow) & 25 \\
\hline $0.523<\operatorname{con}<0.610$ (green) & 15 \\
\hline $0.610<\operatorname{con}<0.697 \quad$ (blue) & 8 \\
\hline
\end{tabular}


With regard to the ascending orbit, the monitored points have maximum and minimum consistency values equal to 0.80 and 0.35 , respectively, while for the descending one the values are 0.70 and 0.35 , respectively. For the ascending orbit $44 \%$ of the points (equal to 48) exceed the average value of approximately 0.49 , while for the descending one the average value of 0.47 is exceeded by $43 \%$ of the 38 observed points. The points with the highest values of both annual velocity and consistency value have been identified as the most relevant and reliable for monitoring purposes. They are the following: ascending orbit ID 17585 and descending orbit ID 152767.

The location of these points is shown in Fig. 7, while their velocity and consistency are shown in Table 5. The time series of the selected points are shown in Fig.s 8-9.

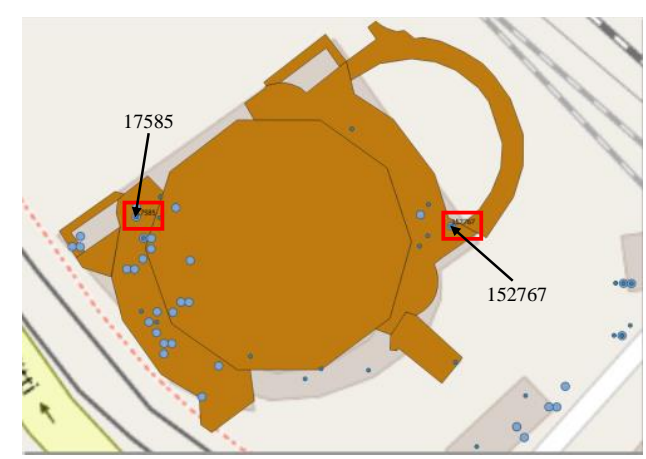

Fig. 7: Points identified for structural monitoring [QGis3.10 A Coruña]

Table 5. Characteristics of the most representative points.

\begin{tabular}{|l|l|l|l|}
\hline Orbit & $\begin{array}{c}\text { Identity } \\
\text { code (ID) }\end{array}$ & $\begin{array}{c}\text { Annual } \\
\text { Velocity } \\
\text { [cm/year] }\end{array}$ & $\begin{array}{c}\text { Consistenc } \\
\mathrm{y}\end{array}$ \\
\hline $\begin{array}{l}\text { Ascending } \\
\text { Descending }\end{array}$ & 17585 & 0.0816 & 0.553 \\
\hline
\end{tabular}

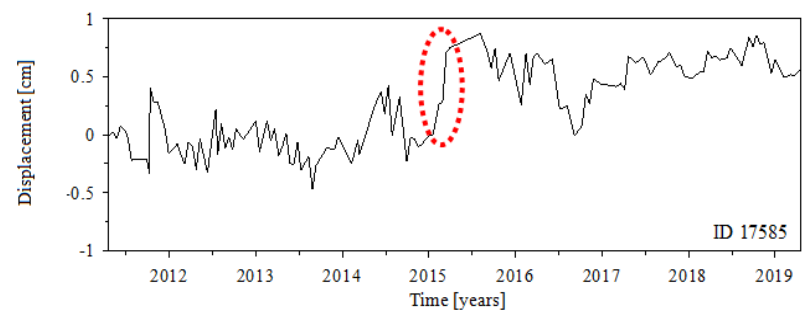

Fig. 8: Distribution of annual velocity values (cm/year) relating to the ascending orbit ID 17585 [QGis3.10 A Coruña]

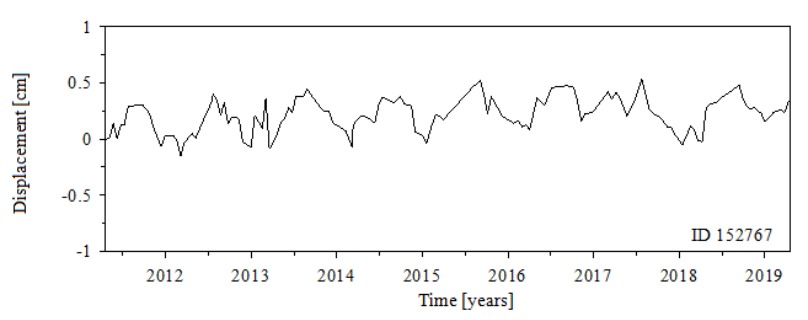

Fig. 9: Distribution of annual velocity values (cm/year) relating to ID 152767 [QGis3.10 A Coruña]

In the first case, the point ID 17585 seems to be affected little by thermal fluctuations due to seasons change. The movement trend is quite irregular and, in particular, in the first part of 2015 it seems to have suffered a permanent deviation of almost $1 \mathrm{~cm}$ (Fig. 8). Instead, in the second case, the time series shown at point ID 152767 , appears to be regularly affected by annual temperature variations (Fig. 9).

\section{Conclusion}

Considering the vast Italian historical and archaeological heritage that requires a careful structural monitoring plan in order to guarantee its conservation, the present research conducted has shown how satellite interferometry is a valid support tool for on-site monitoring campaigns which, in some cases, turn out to be burdensome and expensive.

The adoption of this technique makes it possible to create a temporal archive of data from whose processing it is possible to identify the areas subject to different levels of deformation for the evaluation of the health-state of the structure, and to know its history, studying the development of structural deformations in the aftermath. In this context, the use of satellite series, considering the availability of images with high spatial resolutions, should be included in the structural risk prediction and prevention phase, allowing to identify and map the areas of interest that form the basis for any risk mitigation activity. Future developments intend to evaluate the reliability of the new satellite monitoring methodologies by comparing them with the results obtained with on-site monitoring.

\section{Acknowledgments:}

This research is part of ReLuis Project, DPCReLUIS 2019-2020, WP6 (Monitoring and satellite data), Task 6.3 - Buildings of historical and monumental interest and archaeological areas. 
References:

[1] Cigna, F., Bateson, L. B., Jordan, C. J., Dashwood, C. Simulating SAR geometric distortions and predicting Persistent Scatterer densities for ERS-1/2 and ENVISAT C-band SAR and InSAR applications: Nationwide feasibility assessment to monitor the landmass of Great Britain with SAR imagery, Remote Sensing of Environment, 2014, 152, pp. 441466.

[2] Bru, G., Herrera, G., Tomás, R., Duro, J., De la Vega, R., Mulas, J. Control of deformation of buildings affected by subsidence using persistent scatterer interferometry, Structure and infrastructure engineering, 2013, 9(2), pp.188-200.

[3] Yang, C. H., Kenduiywo, B. K., Soergel, U. Change Detection Based on Persistent Scatterer Interferometry-A New Method of Monitoring Building Changes, ISPRS Annals of Photogrammetry, Remote Sensing \& Spatial Information Sciences, 2016, 3(7).

[4] Arangio, S., Calò, F., Di Mauro, M., Bonano, M., Marsella, M., Manunta, M. An application of the SBAS-DInSAR technique for the assessment of structural damage in the city of Rome, Structure and Infrastructure Engineering, 2014, 10(11), pp. 1469-1483. doi.org/10.1080/15732479.2013.833949

[5] Bonano, M., Manzo, M., Casu, F., Manunta, M., Lanari, R. DinSAR for the monitoring of cultural heritage sites. In: Sensing the Past (pp. 117-134). Springer, Cham. 2017.

[6] De Corso, T., Mignone, L., Sebastianelli, A., Del Rosso, M. P., Yost, C., Ciampa, E., Ullo, S. Application of DInSAR technique to high coherence satellite images for strategic infrastructure monitoring, IGARSS 2020-2020 IEEE International Geoscience and Remote Sensing Symposium IEEE, 2020, pp. 42354238.

[7] Lanari, R., Casu, F., Manzo, M., Zeni, G., Berardino, P., Manunta, M., Pepe, A. An overview of the small baseline subset algorithm: A DInSAR technique for surface deformation analysis, Deformation and Gravity Change: Indicators of Isostasy, Tectonics, Volcanism, and Climate Change, 2007, pp. 637-661. doi.org/10.1007/978-3-7643-84173 2

[8] Zeni, G., Bonano, M., Casu, F., Manunta, M., Manzo, M., Marsella, M., Pepe, A., Lanari, R. Long term deformation analysis of historical buildings through the advanced SBAS DInSAR technique: The case study of the city of Roma
(Italy), Journal of Geophysics and Engineering, 2011, 8(S1). doi:10.1088/1742-2132/8/3/S01

[9] Diaferio, M., Foti, D., Giannoccaro, N.I. Identification of the modal properties of a building of the Greek heritage. Key Engineering Materials, 2014, 628, pp. 150-159. doi:10.4028/www.scientific.net/KEM.628.150

[10] Diaferio, M., Foti, D., Gentile, C., Giannoccaro, N.I., Saisi, A. Dynamic testing of a historical slender building using accelerometers and radar, Proc. of the $6^{\text {th }}$ International Operational Modal Analysis Conference, May 12-14, Gijón, Spain, 2015, paper ID 153, pp.129-130, ISBN: 978-84-6173880-9.

[11] Foti, D. Non-destructive techniques and monitoring for the evolutive damage detection of an ancient masonry structure, Key Engineering Materials, 2014, 628, pp 168-177. doi:10.4028/www.scientific.net/KEM.628.168.

[12] MIT - Ministry of Infrastructures and Trasport, 2018: Ministry Decree of the 17Th Jan 2018. Adjournment of Technical Code Standard for Constructions (in Italian). Supplemento ordinario n. 8 alla Gazzetta Ufficiale del 20-2$2018 . \quad$ Rome, Italy. https://www.gazzettaufficiale.it/eli/id/2018/2/2 0/18A00716/sg

\section{Contribution of Individual Authors to the Creation of a Scientific Article (Ghostwriting Policy)}

Maria Francesca Sabbà, Michela Lerna carried out the conceptualization, the data simulation, the methodology and the Writing - original draft.

Mariella Diaferio was responsible for Writing review \& editing.

Supervision and Project administration Dora Foti.

\section{Sources of Funding for Research Presented in a Scientific Article or Scientific Article Itself}

This research is part of ReLuis Project, DPCReLUIS 2019-2020, WP6 (Monitoring and satellite data), Task 6.3 - Buildings of historical and monumental interest and archaeological areas.

\section{Creative Commons Attribution License 4.0 (Attribution 4.0 International, CC BY 4.0)}

This article is published under the terms of the Creative Commons Attribution License 4.0 https://creativecommons.org/licenses/by/4.0/deed.en US 